\title{
Ciencia, compromiso y cambio social. Textos de Orlando Fals Borda. Nicolás Armando Herrera Farfán y Lorena López Guzmán (Comps.)
}

\author{
El Colectivo-Lanzas y Letras-Extensión libros, Buenos Aires. \\ Argentina, 2013. 460 págs.
}

\section{Luis Martín-Cabrera}

Universidad de California, San Diego.

Email: lmartincabrera@ucsd.edu

Vale la pena empezar esta reseña de Ciencia, compromiso y cambio social señalando lo obvio: Orlando Fals Borda es a la sociología lo que Paolo Freire es a la pedagogía y Frei Beto a la teología, es decir, un pensador de la liberación de los pueblos del sur. En este sentido, tendremos que volver una y otra vez a leer críticamente sus textos en busca de herramientas y lenguajes que sigan abonando el terreno de la rebelión popular, las transformaciones y la descolonización en Colombia y en América Latina.

Este volumen prologado y editado por Nicolás Armando Farfán y Lorena López Guzmán tiene, de partida, la virtud de no haber tratado de ser una antología exhaustiva, genealógica y totalizante de la ingente obra de Fals Borda. El libro está organizado, siguiendo la estructura de una de las novelas favoritas del propio Fals Borda, como una rayuela cortazariana. Por ende, el lector/a puede entrar desde distintas puertas y saltando para delante y para atrás, profundizando más o menos, en los distintos conceptos que conforman el pensamiento sociológico de Fals Borda. Las secciones del libro -teoría, metodología y praxiología-están precedidas por una conmovedora introducción de los editores y por una carta y una entrevista del antologado a modo de autopresentación. Cada una de las secciones presenta una miríada de textos de distinta índole (entrevistas, conferencias, capítulos de libros, intervenciones públicas, ensayos etc.) que constituyen las principales contribuciones de Fals Borda a la creación de una sociología transformadora, descolonizada y anclada en las realidades materiales y las visiones del mundo de los sectores populares de Colombia.

En este sentido, el libro permite reconstruir tanto la fascinante trayectoria política y académica de Fals Borda desde los años setenta en adelante como sus principales conceptos y herramientas metodológicas para la construcción de una sociología primordialmente latinoamericana y decididamente emancipatoria. Estos conceptos serían fundamentalmente los de "subversión”, “anti-élite”, el método "Investigación-Acción-Participación 
(IAP)” y la apuesta por un socialismo raizal y descolonizado. Todas estas aportaciones tienen en común el partir de una ruptura con las dicotomías del pensamiento racional cartesiano -sujeto/objeto, teoría/praxis, razón/ emoción, mente/cuerpo-que sostenían y sostienen el edificio epistemológico del funcionalismo y el empiricismo radical en las ciencias sociales. En el origen de este desplazamiento de las categorías cartesianas hay tanto un problema hermenéutico como político, ya que éstas, ni se adecuan analíticamente a las realidades de América Latina ni pueden servir para poner fin a la explotación y la opresión de los sectores populares de la región; su halo de objetividad no es más que un disfraz que oculta la dominación y la reproducción del status quo y, por lo tanto, el apuntalamiento de los privilegios de las clases dominantes.

Examinemos someramente estos ejes fundamentales del pensamiento del sociólogo colombiano. Después del último ciclo de dictaduras en América Latina la palabra “subversión” pasó a designar a todos aquellos sectores de la sociedad civil comprometidos con proyectos revolucionarios y profundas transformaciones sociales que sacaran a los países del subcontinente de la dependencia colonial. De este modo, la gramática del horror dictatorial transformó la palabra subversión en un vocablo abyecto que designaba a aquellos sujetos “infrahumanos” a los que se podía exterminar y hacer desaparecer con total impunidad en campos de concentración como la infame ESMA (Escuela de Mecánica de la Armada) de Argentina o el Estadio Nacional en Chile. A Fals Borda hay que agradecerle el haber sacado la palabra "subversivo" del lodazal moral en el que la habían sumido los militares golpistas para dotarla de contenido ético y teórico. Al contrario de lo que postulan los militares y las burguesías oligárquicas que los apoyan, la subversión es un deber moral cuando el orden establecido se funda, como sucede en la mayoría de las sociedades latinoamericanas, en la exclusión y explotación de los sectores populares. Atreverse a decir que la subversión es un deber moral y postular una sociología subversiva que dote de herramientas a los movimientos sociales en un país como Colombia es un acto de coraje intelectual y político que no debe pasarnos desapercibido a sus lectores contemporáneos.

La subversión tiene que ser el fundamento teórico y moral que abone la formación de una anti-élite. La anti-élite, como la define Fals Borda, es una clase dentro de la clase dominante que debe aspirar a desclasarse, es decir, que debe adoptar como fundamento teórico de su accionar la subversión de los valores dominantes de la sociedad. Por eso, el intelectual antielitista debe instalarse en las instituciones para subvertir y boicotear la reproducción y la naturalización de las aberrantes injusticias y desigualdades que definen el orden social en América Latina. En este sentido, el intelectual anti-elitista sirve de puente y de mediador entre las demandas de los sectores populares y los valores de la élite, su función es la de catalizador de la destrucción de los privilegios de las clases dominantes mediante la creación de antivalores y contranormas que puedan facilitar la emancipación de las clases subalternas. El anti-intelectual es, por tanto, como un virus que aspira a volver la dominación inoperativa sin que ello implique 
necesariamente "hablar por" los oprimidos o ser representante de sus demandas.

Estos conceptos teóricos, así como el deseo de construir una ciencia social que no quede sujeta ni dependiente de los modelos europeos y norteamericanos, es lo que está detrás de la creación del método de investigación sociológico “Investigación-Acción-Participación (IAP)”. IAP es, de partida, un intento de crear una sociología descolonizada, vale decir, una sociología que no adapte mecánicamente modelos occidentales para entender fenómenos latinoamericanos, una sociología endógena que renuncie a sus pretensiones de objetividad y que rompa con las dicotomías sujetoobjeto y teoría-praxis. El sociólogo funcionalista del norte tendía a construirse como sujeto externo y neutral a la realidad objetiva que estudiaba. Esta pretendida neutralidad, según Fals Borda, es consciente o inconscientemente una manera de reproducir y naturalizar la explotación de las grandes masas populares. Por eso, en el IAP el sociólogo debe romper con la distinción cartesiana entre sujeto y objeto, mancharse las manos con la tierra y el trabajo de campo, romper la frontera sujeto-objeto y trabajar en pos de la liberación colectiva de las comunidades que estudia. El sociólogo no puede ser observador pasivo de la realidad fundamentalmente dolorosa y desesperanzada en la que vive y tampoco puede producir simplemente un conocimiento empírico y acumulativo que circule sólo dentro de los elitistas recintos universitarios sin tener ninguna incidencia en las comunidades que estudia.

Aunque parezca absolutamente evidente vale la pena insistir, con Fals Borda, en que las clases populares --los campesinos, las mujeres, los indígenas, los obreros o los afrodescendientes — son también productores y portadores de un conocimiento propio. La ciencia social se debe retroalimentar de este conocimiento, debe, por un lado, adaptar y crear sus propios métodos de análisis social y, por otro lado, alimentarse del conocimiento, la cultura y los imaginarios de las clases subalternas con las que produce conocimiento y no sobre las que produce conocimiento. Pero con eso no basta, si el conocimiento no viene acompañado de una praxis emancipadora es conocimiento inerte; la investigación sociológica debe fundarse, por ello, sobre la acción para que sirva a las comunidades explotadas y porque la separación entre teoría y praxis es una mutilación epistemológica que ni deja pensar ni puede liberarnos de la explotación capitalista y de la dominación imperial.

En el método "Investigación-Acción-Participación (IAP)” está implícita una concepción del poder que se anticipa en varios años a las teorías del pensador Michel Foucault. Dicho de manera simplista, la relación entre conocimiento y poder, la producción de conocimiento a través de múltiples discursos como producción de poder que vertebra toda la obra de Michel Foucault y que ha tenido gran incidencia en las universidades del norte, aparece decididamente y mucho antes en la obra de Fals Borda en relación a los sectores subalternos de Colombia y América Latina. Fals Borda se da cuenta, desde sus primeros trabajos en la costa Atlántica, de que los cam- 
pesinos deben dejar de estar cruzados por toda una serie de discursos sociológicos, porque éstos no solo "les explican” sino que también contribuyen a su explotación y dominación. Mientras los campesinos de la costa Atlántica sean objeto de investigación y no sujetos de su propia historia y su propio conocimiento estarán condenados a la marginación y no podrán empoderarse para romper las cadenas que les sujetan al modo de producción capitalista.

Pero Fals Borda no se conforma con romper las dicotomías del pensamiento racional cartesiano, con hacer de la praxis teoría y de la teoría acción, ni tampoco le basta con invertir la producción de conocimiento sociológico y poner las instituciones universitarias al servicio de la emancipación de los pueblos, sino que aboga por que estas herramientas sociológicas cristalicen en una utopía socialista. El socialismo raizal que propone Fals Borda debe construirse desde abajo, con voluntad radicalmente democrática y participativa y sin importar modelos o recetas de socialismo foráneo que no hacen sino distorsionar la historia y las realidades latinoamericanas. El socialismo de Fals Borda es radicalmente anticapitalista y decolonial; tiene amplitud de miras, porque, sin dejar de hacer una crítica constructiva, es capaz de extraer lecciones del modelo cubano, de las experiencias de la revolución sandinista en Nicaragua y también, por supuesto, de las luchas sociales en Colombia y en otras latitudes de América Latina y del Tercer Mundo.

Sorprende -y tal vez deba ser objeto de un debate más amplio-la obstinación de Fals Borda en mantener el estatus de ciencia y el carácter universalista de su quehacer sociológico. El asunto es complicado, porque, por un lado, Fals Borda rechaza el estatus de ciencia de la sociología cuando se aplican los protocolos de observación, experimentación, objetividad y neutralidad de las ciencias naturales, en parte, porque los sistemas sociales son mucho más abiertos e inestables que los ecosistemas y, sobre todo, porque el observador en las ciencias sociales es parte de la realidad observada e, inevitablemente, proyecta sus prejuicios, sus deseos y sus emociones sobre dicha realidad (Fals Borda insiste, una y otra vez en sus escritos, en señalar que el sociólogo que se pretende neutral y objetivo termina siempre por ser subjetivo y portavoz, consciente o inconsciente, del discurso hegemónico). Pero en lugar de deconstruir el estatuto científico de la sociología, Fals Borda pone todo su empeño en crear una ciencia social que se adecue a las realidades de América Latina y sobre todo que pueda servir como herramienta para la emancipación de los pueblos. Para ello, rompe con el empiricismo positivista fundado por Comte, pero busca en el empirismo de Francis Bacon las claves de una sociología que parta de lo concreto observable en general y de la praxis en particular para formular sus hipótesis. Podríamos preguntarnos por qué América Latina no ha de tener una ciencia social con características propias o por qué habría de quedar reducida al lugar de la sinrazón, por qué regalarle el estatus de ciencia a Europa y Norteamérica, por qué no apropiarse de los protocolos y las metodologías que puedan servir como herramientas de emancipación en América Latina. Sospecho que esa sería la respuesta de Fals Borda, pero también podemos 
preguntarnos si el marbete de ciencia puede contener la inmensa heterogeneidad de conocimientos que se producen en y sobre las realidades latinoamericanas. Por ejemplo, ¿Cabrían en la categoría de ciencia los diferentes modos de conocimiento que muchas culturas indígenas de las Américas denominan espiritualidad? ¿Cabría el tiempo cíclico de la emancipación que los aimaras denominan "pachakuti”? ¿Cómo podría verificarse científicamente una categoría tan importante para el futuro ecológico de la región como la de "buen vivir"? Tal vez no se trate tanto de abandonar la ciencia, sino de entender sus límites.

Por momentos la sociología de Fals Borda parece pretender engullirlo todo, subordinar la literatura, la antropología, la psicología, la economía, los saberes en general a un método sociológico que, como hemos descrito arriba, sigue evidentemente conteniendo elementos claves para la emancipación. Sin embargo, su pretensión universal presenta también puntos ciegos que habría que teorizar colectivamente. Fals Borda insiste en que anclar la ciencia social en las realidades concretas de América Latina no implica excluirlas de la totalidad universal. Estos rastros de hegelianismo en el pensamiento sociológico de Fals Borda también habría que revisarlos, no tanto por excluir lo latinoamericano particular de lo universal, sino porque no quedan teorizadas suficientemente las relaciones entre lo particular y lo universal, por un lado, y entre las distintas partes de lo particular que supuestamente conforman lo universal, por otro. Habría que preguntarse si lo particular alemán tiene el mismo estatus que lo particular colombiano. No trato de emboscarme en una discusión abstracta e impenetrable, sino que creo fundamental poder cuestionar las relaciones de poder implícitas en los conceptos que utilizamos para pensar y actuar la liberación de las grandes masas explotadas en América Latina. Definitivamente, no podemos regarle todos los conceptos teóricos a Europa, porque sería otra forma de desposesión y saqueo colonial, pero debemos seguir preguntando con la misma insistencia que lo hizo Fals Borda, quién legitima a los legitimadores. 